\title{
The effect of supplier performance and transformational supply chain leadership style on supply chain performance in manufacturing companies
}

\author{
Agus Purwanto ${ }^{a^{*}}$ and Juliana ${ }^{\mathrm{a}}$
}

${ }^{a}$ Pelita Harapan University, Tangerang, Indonesia

\begin{tabular}{l}
\hline A B S T R A C T \\
\hline Article history: \\
Received October 1,2021 \\
Received in revised format \\
October 25,2021 \\
Accepted December 22021 \\
Available online \\
December 22021 \\
\hline Keywords: \\
Supplier performance \\
Transformational supply chain \\
leadership \\
Supply chain performance
\end{tabular}

\section{Introduction}

In the era of the industrial revolution 4.0 and society 5.0, the desire of a company to always compete, improve company performance and be successful in the long term has forced companies to enter cooperative relationships with suppliers since it is impossible for a firm to produce everything needed. with suppliers this has become a necessity in today's competition where competition occurs in all supply chain networks of a company, which implies that large companies are very dependent on their smallest partners. To get a supply chain that has flexibility and responsiveness, an organization needs to implement integration with suppliers. Ali et al. (2017) and Aunyawong et al. (2020) stated that investment in integration with suppliers has the potential to provide higher operational performance than investment in integration with customers. Although the relationship between buyers and suppliers is important for improving the performance of both parties, there is always a potential for failure due to various factors. According to Asamoah et al. (2021) and Bag et al. (2020), in the relationship between buyers and suppliers, it is necessary to examine the effect of supply chain strategy on supplier performance from the buyer's side in addition to the buyer's supply chain performance. Several previous studies gave different results in examining the relationship of supply chain integration, especially integration with suppliers on performance, such as Belhadi et al. (2021); Chowdhury et al. (2019); Chienwattanasook et al. (2018) which state that there is a positive relationship between the implementation of supply chain integration and improving the supply chain performance. In addition, there are also several studies that state differently that the implementation of supply chain integration, especially supplier integration, does not significantly affect company performance (e.g., Dalporto et al., 2020; Dossou et al., 2017; Dissanayake et al., 2018; Fatorachian et al., 2021; Goel et al., 2021; George et al., 2019). Some studies also provide a negative relationship between

* Corresponding author

E-mail address: aguspurwanto.prof@gmail.com (A. Purwanto)

(C) 2022 Growing Science Ltd. All rights reserved.

doi: $10.5267 /$ j.uscm.2021.12.001
The purpose of this study is to analyze the relationship between supplier performance and supply company analysis unit represented by one of the managers in the chain management section. The population in this study is a manufacturing company in Tangerang. Two hundred and fifty online questionnaires were distributed to each company and 220 eligible respondents were tested. Based on the results of data analysis, it is found that there is a positive and significant relationship
between supplier performance and supply chain performance, a positive and significant relationship exists between transformational supply chain leadership and supply chain
performance and there is a positive and significant relationship between supplier performance and transformational supply chain leadership. between supplier performance and transformational supply chain leadership. The study uses a 
company performance and supply chain management (Belhadi et al., 2021; Chowdhury et al., 2019; Chienwattanasook, et al., 2018). Several studies explain the performance parameters of suppliers from the buyer's side, such as flexibility and innovation, cost reduction, supply, innovative problem solving skills and creative thinking skills, analytical thinking skills in communication. In addition, Prahinski and Benton (2004) distinguished two streams for measuring supplier performance, namely competitive success factors (e.g., quality, delivery, price, service, and flexibility) and internal indicators such as defects, delivery realization and additional costs. With a focus on ICT (Information Communication Technology), information sharing, and collaboration, supplier performance is conceptualized as how well suppliers perform about operational delivery in accuracy and speed, not defects and cost efficiency. Likewise, research in the field regarding the relationship between ICT and performance, it is known that supplier performance is a measure of an important competitive success factor in operations. To understand the causes of the unequal influence of supplier performance in supply chain management, it is necessary to know things related to supply chain leaders in carrying out supply chain strategies according to research by Fatorachian et al. (2021); Goel et al. (2021); George et al. (2019) because leadership is indispensable in the supply chain as the key to successful strategy and competitive advantage as well as success in buyer and supplier relationships. Several studies also mention that organizational culture and leadership are closely related.

Leadership is always described as behavior and personal traits that are unconsciously needed to influence the process of a relationship. This causes the manager's leadership style to be an important factor in supply chain leadership that not only affects the company but also the entire supply chain including suppliers, Supply chain leadership style in general differentiated into transactional leadership style and transformational leadership style. According to Mani et al. (2018); Ngouapagne et al. (2019); Nugraha et al. (2019); Sánchez et al. (2020); Singhry et al. (2019), transactional leadership is a traditional leadership that focuses on changes that occur between leaders and followers, where this change allows leaders to achieve their performance targets, complete required tasks, maintain organizational conditions, motivate followers through contractual agreements, ensure direct behavior of followers towards achieving the set targets, emphasizing external rewards, avoiding unnecessary risks, and focusing on increasing organizational efficiency while transformational leadership more often shows four components, namely influencing through ideas, inspiring and motivating, providing intellectual stimulation, and providing individual consideration. Based on this definition, transactional leadership style is the embodiment of organizational culture itself which is in line with the research of Mofokeng et al. (2019); Ngouapagne et al. (2019); Nugraha et al. (2019); Sánchez et al. (2020); Singhry et al. (2019) which states that organizational culture will affect transactional leadership style. The transactional leadership style does not develop long-term relationships since performance is based on the leader's targets and rewards, while the transformational leadership style focuses on influencing through motivation and inspiration to produce innovations that can influence the development culture and group culture. According to Nugraha et al. (2019); Sánchez et al. (2020) and Singhry et al. (2019), the supply chain transformational leadership style will also play a role in improving the quality of integration with suppliers and maintaining long-term relationships with suppliers as well as the broad application of supply chain management strategies because the transformational leadership style directs followers with motivation through mindset changes so that the expected performance can last in the long run. Based on the gap from previous research regarding the influence of supplier performance in supply chain management, this study uses transformational supply chain leadership style as a moderating variable that can strengthen or weaken the influence of supplier performance on the company's supply chain performance and strengthen previous research that leadership style is positively related to performance. company

The purpose of this study is to analyze the relationship between supplier performance to supply chain performance, transformational supply chain leadership to supply chain performance, supplier performance to transformational supply chain leadership.

\section{Method}

This study uses hypothesis testing that examines the relationship between two or more variables expressed in the form of statements that represent each variable so that conclusions can be obtained from research conducted by Sekaran \& Bougie (2016). Based on the strategy used in research, this research includes survey research that collects information from or about people to describe, compare, or explain their knowledge, attitudes and behavior. This study uses a company analysis unit represented by one of the managers in the chain management section. Based on the time horizon, this research is a cross sectional study where data is only collected once in a certain period. The research period is from July - August 2021 . The population in this study is a manufacturing company in Tangerang. Two hundred and fifty questionnaires were distributed to each company and 220 respondents were eligible to be tested.

The hypothesis in this study is

H1: Supplier performance has a positive effect on supply chain performance.

$\mathbf{H}_{2}$ : Transformational Supply Chain Leadership has a positive effect on supply chain performance.

H3: Supplier performance has a positive effect on Transformational Supply Chain Leadership. 


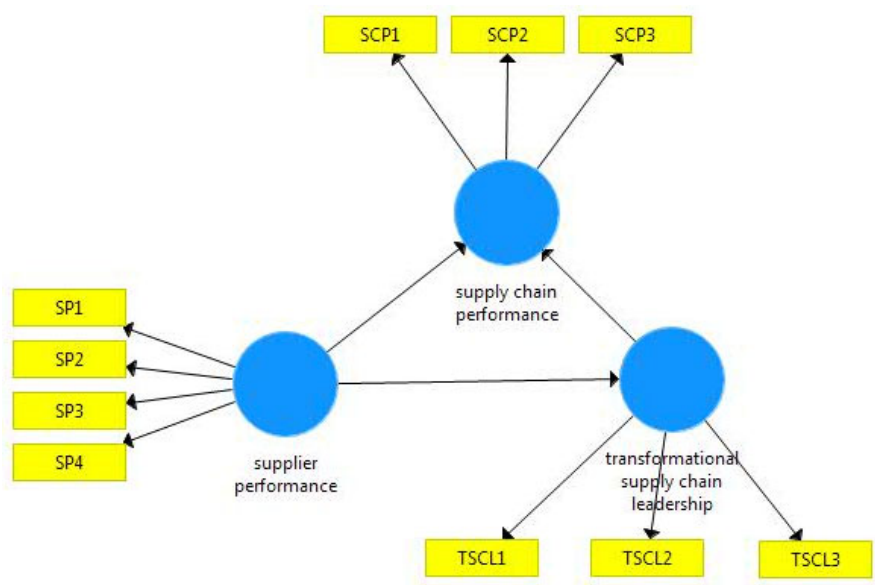

Fig. 1. Research Model

\section{Result and Discussion}

\subsection{Test Outer Model}

\section{Convergent Validity}

In testing the convergent validity, it is said to be valid if the value on the outer loading of each indicator is correlated more than 0.7 according to Purwanto et al. (2021). Fig. 2 shows the loading factor value of the model which has been made through Smart-PLS 3.0. The results of the image above show the value of each tested indicator has a value of $>0.7$. So it can be concluded that all indicators have valid results.

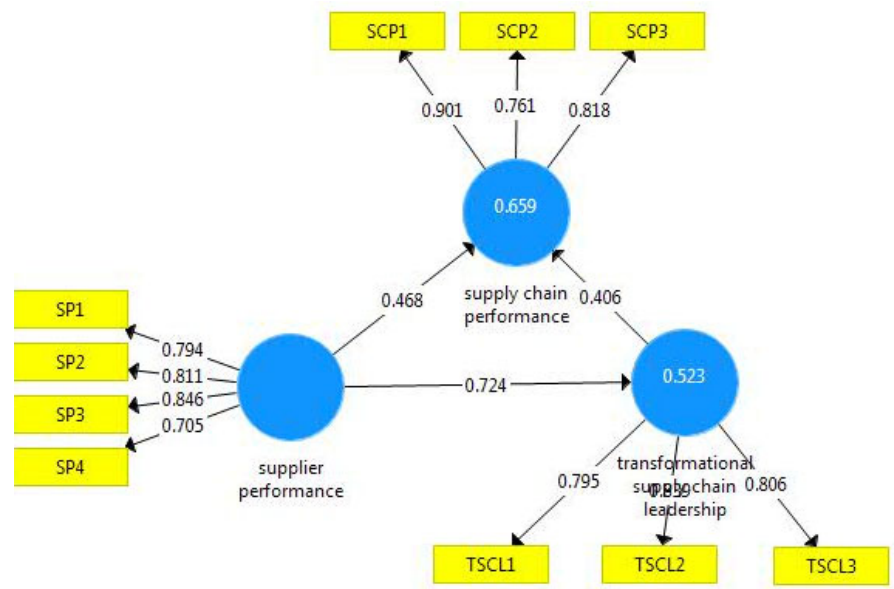

Fig. 2. Validity Testing

\subsection{Discriminant Validity}

Discriminant validity is carried out to ensure that each concept of each latent variable is different from other latent variables. The discriminant validity of the measurement model with reflective indicators is assessed based on the cross loading of measurements with variables (Purwanto et al., 2020) The model has good discriminant validity if the loading value of each the latent variable indicator has the largest loading value compared to other loading values for other latent variables. From the results of the discriminant validity test, each latent construct indicator has the largest loading factor value when compared to other loading values so that the model has a good discriminant validity value, which is $>0.7$ for each variable (Purwanto, 2019).

\subsection{Reliability}

Reliability testing aims to determine the size of a test that has consistent and stable results every time (Purwanto et al., 2021). The reliability of the measurement model 5 gets good results if the value is more than the rule of thumbs alpha value or composite reliability $>0.6$ (Purwanto et al., 2021). 
Table 1

Items Loadings, Cronbach's Alpha, Composite Reliability, and Average Variance Extracted (AVE)

\begin{tabular}{llll}
\hline Variables & Cronbach's Alpha & Rho A & Composite Reliability \\
\hline Supplier performance & 0.858 & 0.878 & 0.887 \\
Transformational Supply Chain Leadership & 0.866 & 0.866 & 0.676 \\
Supply chain performance & 0.859 & 0.857 & 0.812 \\
\hline
\end{tabular}

\subsection{Inner model test}

Inner model test can be done in three ways by looking at $\mathrm{R}^{2}, \mathrm{Q}^{2}$ and GoF.

\subsubsection{Inner Model Test (R-square)}

The coefficient of determination is used to determine the magnitude of the relationship between the independent variable and the dependent variable.

Table 2

The results of R-Square

\begin{tabular}{lcc}
\hline & R Square & R Square Adjusted \\
\hline Transformational Supply Chain Leadership & 0.232 & 0.224 \\
Supply chain performance & 0.406 & 0.396 \\
\hline
\end{tabular}

Based on the calculation results in the table shows $40.6 \%$ of the dependent variable is influenced by the proposed model (independent variable). While the remaining value of $59.4 \%$ is owned by variables that are outside the model. $40.6 \%$ of the dependent variable is influenced by the proposed model (independent variable). While the remaining value of $59.4 \%$ is owned by variables that are outside the model.

\subsubsection{Inner Model Predictive Relevance Test (Q2)}

Inner model predictive relevance (Q2) test was conducted to determine the relative effect of the structural model on the measurement of latent variable observations. The value in the predictive relevance (Q2) model is said to have predictive relevance if the results of Q2 $>0$ observation measurements have been reconstructed properly. However, the value of Q2 < 0 cannot be said to be predictive of relevance. The following are the results of the calculation of the Q2 value from the previously created model. The results of the calculation of Q2 show that the value of Q2 $>0$. That the model that has been made has predictive relevance.

\subsubsection{Goodness of Fit (GoF)}

The Goodness of Fit (GoF) inner model test is used to find the Goodness of Fit (GoF) value. The GoF value in PLS-SEM must be searched manually. Tenenhaus, (2004) says that the inner goodness of fit test has three criteria, namely small (0.1), medium (0.25) and large (0.38). Goodness of Fit (GoF) test is conducted to determine the feasibility of a model. The following is looking for the Goodness of Fit $(\mathrm{GoF})$ value as follows: $=0.56$ Based on the calculation, the GoF above can be concluded that the GoF value obtained is 0.56 including in the large category. So the model is declared fit.

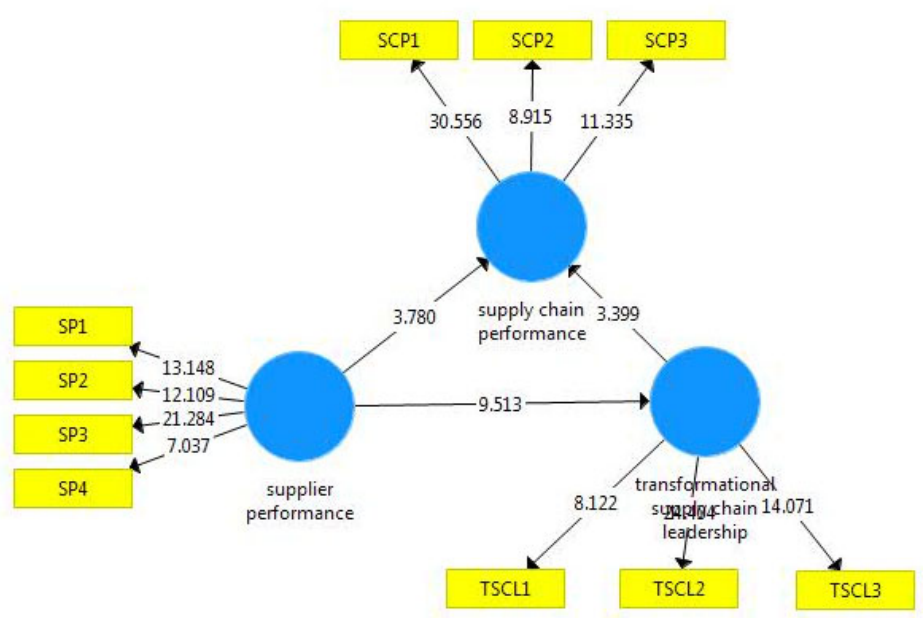

Fig. 3. Hypothesis Testing 
Hypothesis Testing Hypothesis testing, or significance testing aims to assess the effect of the relationship between variables. Statistical testing of each hypothesized relationship was carried out using a bootstrapping simulation. The table shows the results of the bootstrapping simulation

Based on the table above, the overall composite reliability value for each variable is $>0.6$. Thus, it can be concluded that the measurement model of each variable has good reliability. As for the AVE value, each variable has a value of more than 0.5 so it can be concluded that the discriminant requirement is achieved. Average Variance Extracted (AVE) is the average percentage of a variance explained by items in a construct.

Table 3

Hypotheses Testing

\begin{tabular}{llll}
\hline Hypotheses & Relationship & Decision \\
\hline $\mathrm{H}_{1}$ & Supplier performance has a positive effect on supply chain performance. & P-Value & 0.000 \\
$\mathrm{H}_{2}$ & Transformational Supply Chain Leadership has a positive effect on supply chain performance. & Supported \\
$\mathrm{H}_{3}$ & Supplier performance has a positive effect on Transformational Supply Chain Leadership. & 0.001 & Supported \\
\hline
\end{tabular}

\section{Results and Discussion}

\section{$\mathrm{H}_{1}$ : Supplier performance has a positive effect on supply chain performance.}

Based on the results of data analysis, it was obtained that the p value was $0.000<0.050$ and it was concluded that there was a positive and significant relationship between supplier performance and supply chain performance. This result is in line with Mani et al. (2018); Maestrini et al. (2017); Mokhtar et al. (2019); Mofopeng et al. (2019). The positive and significant relationship between supplier performance and supply chain performance is also supported by Ngouapegne et al. (2019); Nugraha et al. (2019); Sánchez et al. (2020); Singhry et al. (2019). Improved supplier performance will lead to a significant increase in supply chain performance.

\section{$\mathrm{H}_{2}$ : Transformational Supply Chain Leadership has a positive effect on supply chain performance.}

Based on the results of data analysis, it was found that the $\mathrm{p}$ value was $0.000<0.050$ so it was concluded that there was a positive and significant relationship between transformational supply chain leadership and supply chain performance, this result is in line with Gezgin et al. (2017); Hove-Sibanda et al. (2018); Kamble et al. (2021). Moreover, Kumar et al. (2019); Khyzer et al. (2018) and Lima-Junior et al. (2017) also confirm that there was a positive and significant relationship between transformational supply chain leadership and supply chain performance. Improved Transformational Supply Chain Leadership will drive a significant increase in supply chain performance.

\section{$\mathrm{H}_{3}$ : Supplier performance has a positive effect on Transformational Supply Chain Leadership.}

Based on the results of data analysis, it is found that the $p$ value is $0.000<0.050$ so it can be concluded that there is a positive and significant relationship between supplier performance and transformational supply chain leadership. These results are in line with Fatorachian et al. (2021); Goel et al. (2021); George et al. (2019). There are also other studies that state there is a positive and significant relationship between supplier performance and transformational supply chain leadership (Dalporto et al., 2020; Dossou et al., 2017).

\section{Conclusion}

Based on the results of data analysis, we have found that there is a positive and significant relationship between supplier performance and supply chain performance, there is a positive and significant relationship between transformational supply chain leadership and supply chain performance and finally, there is a positive and significant relationship between supplier performance and transformational supply chain leadership.

\section{References}

Ali, H., Siddiqui, F. A., \& Saeed, M. A. (2017). Succession Planning for Supply Chain Leadership; Corporate Sector Perspective. International Journal of Research Scholars, 1(1), 1-7.

Aunyawong, W., Wararatchai, P., \& Hotrawaisaya, C. (2020). The Influence of Supply Chain Integration on Supply Chain Performance of Auto-Parts Manufacturers in Thailand: A Mediation Approach. International Journal of Supply Chain Management, 9(3), 578-590.

Asamoah, D., Agyei-Owusu, B., Andoh-Baidoo, F. K., \& Ayaburi, E. (2021). Inter-organizational systems use and supply chain performance: Mediating role of supply chain management capabilities. International journal of information management, 58, 102195.

Bag, S., Wood, L. C., Xu, L., Dhamija, P., \& Kayikci, Y. (2020). Big data analytics as an operational excellence approach to enhance sustainable supply chain performance. Resources, Conservation and Recycling, 153, 104559. 
Belhadi, A., Kamble, S., Gunasekaran, A., \& Mani, V. (2021). Analyzing the mediating role of organizational ambidexterity and digital business transformation on industry 4.0 capabilities and sustainable supply chain performance. Supply Chain Management: An International Journal.

Chowdhury, M. M. H., Quaddus, M., \& Agarwal, R. (2019). Supply chain resilience for performance: role of relational practices and network complexities. Supply Chain Management: An International Journal, 24(5), 659-676.

Chienwattanasook, K., \& Jermsittiparsert, K. (2018). Supply chain integration, supply chain risk practices and supply chain performance: a contingent view. Opcion, 34(86), 2160-2177.

Dalporto, A., \& Venn, R. (2020). Supply chain leadership, transparency, workforce development and collaboration through control tower implementation. Journal of Supply Chain Management, Logistics and Procurement, 3(1), 66-76.

Dossou, P. E., \& Nachidi, M. (2017). Modeling supply chain performance. Procedia Manufacturing, 11, 838-845.

Dissanayake, C. K., \& Cross, J. A. (2018). Systematic mechanism for identifying the relative impact of supply chain performance areas on the overall supply chain performance using SCOR model and SEM. International Journal of Production Economics, 201, 102-115.

Fatorachian, H., \& Kazemi, H. (2021). Impact of Industry 4.0 on supply chain performance. Production Planning \& Control, 32(1), 63-81.

Goel, R. K., Saunoris, J. W., \& Goel, S. S. (2021). Supply chain performance and economic growth: The impact of COVID19 disruptions. Journal of Policy Modeling, 43(2), 298-316.

George, J., \& Pillai, V. M. (2019). A study of factors affecting supply chain performance. In Journal of Physics: Conference Series (Vol. 1355, No. 1, p. 012018). IOP Publishing.

Gezgin, E., Huang, X., Samal, P., \& Silva, I. (2017). Digital transformation: Raising supply-chain performance to new levels. McKinsey \& Company, 1-10.

Hove-Sibanda, P., \& Pooe, R. D. (2018). Enhancing supply chain performance through supply chain practices. Journal of Transport and Supply Chain Management, 12(1), 1-13.

Kamble, S. S., Gunasekaran, A., Subramanian, N., Ghadge, A., Belhadi, A., \& Venkatesh, M. (2021). Blockchain technology's impact on supply chain integration and sustainable supply chain performance: evidence from the automotive industry. Annals of Operations Research, 1-26.

Kumar, V., Kumar, V., Rao, Y. V., \& Veeramalla, S. (2019). Supply Chain Performance influencer in construction domain: A Key factor analysis: Supply Chain Performance influencer. International Journal of Supply Chain Management, 4(1), $1-7$.

Khyzer Bin Dost, M., Rehman, C., Gilaninia, S., Bte Ismail, K., \& Wasim Akram, M. (2018). The impact of knowledge management's practices on supply chain performance of the dairy sector in Central Punjab: a mediating role of decentralization. Economic research-Ekonomska istraživanja, 31(1), 290-312.

Lima-Junior, F. R., \& Carpinetti, L. C. R. (2017). Quantitative models for supply chain performance evaluation: A literature review. Computers \& Industrial Engineering, 113, 333-346.

Mani, V., Gunasekaran, A., \& Delgado, C. (2018). Enhancing supply chain performance through supplier social sustainability: An emerging economy perspective. International Journal of Production Economics, 195, $259-272$.

Maestrini, V., Luzzini, D., Maccarrone, P., \& Caniato, F. (2017). Supply chain performance measurement systems: A systematic review and research agenda. International Journal of Production Economics, 183, 299-315.

Mokhtar, A. R. M., Genovese, A., Brint, A., \& Kumar, N. (2019). Supply chain leadership: A systematic literature review and a research agenda. International Journal of Production Economics, 216, 255-273.

Mofokeng, T. M., \& Chinomona, R. (2019). Supply chain partnership, supply chain collaboration and supply chain integration as the antecedents of supply chain performance. South African Journal of Business Management, 50(1), 1-10.

Ngouapegne, C. N. M., \& Chinomona, E. (2019). Modelling the influence of the drivers of supply chain performance in the food retail industry in South Africa. Journal of Applied Business Research (JABR), 35(2), 43-62.

Nugraha, A. T., Elmanizar, H. F., Widiyanti, M., Guntoro, R., \& Sulastri, S. (2019). The role of the risk management committee in managing supply chain risk and enhancing supply chain performance: an emerging market perspective. International Journal of Supply Chain Management (IJSCM), 8(1), 319-327.

Sánchez-Flores, R. B., Ojeda-Benítez, S., Cruz-Sotelo, S. E., \& Navarro-González, C. R. (2020). Supply chain performance improvement: A Sustainable perspective. In Techniques, tools and methodologies applied to global supply chain ecosystems (pp. 333-358). Springer, Cham.

Singhry, H. B., \& Abd Rahman, A. (2019). Enhancing supply chain performance through collaborative planning, forecasting, and replenishment. Business Process Management Journal, 25(4), 625-646.

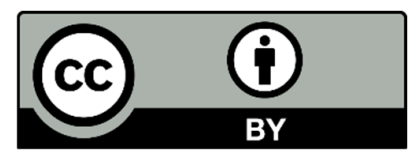

(C) 2022 by the authors; licensee Growing Science, Canada. This is an open access article distributed under the terms and conditions of the Creative Commons Attribution (CCBY) license (http://creativecommons.org/licenses/by/4.0/). 